\title{
Postmortem Study on Indigestible Foreign Bodies in Rumen and Reticulum of Ruminants Slaughtered at Asella Municipal Abattoir, Southeastern Ethiopia
}

\author{
Endale Teshome ${ }^{1}$, Nejash Abdela ${ }^{1 *}$ and Abdi Hassan ${ }^{2}$ \\ ${ }^{1}$ School of Veterinary Medicine, College of Agriculture and Veterinary Medicine, Jimma University, Jimma, Ethiopia \\ ${ }^{2}$ Haramaya University, Haramaya, Ethiopia
}

\begin{abstract}
Background: Ingestion of indigestible foreign bodies by ruminants is becoming a common worldwide problem which is the associated with a shortage of feed as well as increased pollution of grazing lands with indigestible materials.

Methods: Cross-sectional study was conducted from November 2016 to January 2017 on 500 ruminants slaughtered at Asella municipal abattoir with the objective to determine the prevalence and type of indigestible foreign body in rumen and reticulum of ruminants in association with hypothetical risk factors. Simple random sampling technique was used for selecting the study animals which were ruminants brought from various localities to Asella municipal abattoir. Logistic regression was used to determine the association of risk factors with occurrence of for foreign body.
\end{abstract}

Results: Out of 500 ruminant examined (sheep 240, goats 60 and cattle 200) examined for the presence of indigestible foreign bodies, $109(21.8 \%)$ animals were found positive for one or more indigestible foreign bodies in their rumen or reticulum. The prevalence of foreign bodies was significantly $(p=0.000)$ higher in sheep $(29.6 \%)$ $(\mathrm{OR}=2.581, \mathrm{Cl}=1.587,4.196)$ and goat $(16.7 \%)(\mathrm{OR}=1.229, \mathrm{Cl}=0.559,2.701)$ than cattle $(14 \%)$. Multivariable logistic regression analysis revealed that the risk of foreign body ingestion was insignificantly higher in sheep than goats $(\mathrm{OR}=2.074, \mathrm{Cl}, 0.958,4.486 ; \mathrm{p}=0.064)$, in female shoat than male $(\mathrm{OR}=1.137, \mathrm{Cl}=0.558,2.317, \mathrm{p}=0.723)$. Significantly highest prevalence was observed in shoat greater than 3 years than shoat less than 2 years $(\mathrm{OR}=2.564$ $\mathrm{Cl}=1.160,5.670, p=0.031)$, in thin body conditioned small ruminants than good body conditioned (OR=3.361, $\mathrm{Cl}=1.554,9.100, p=0.002)$, in cattle above 7 years than cattle below 4 years $(\mathrm{OR}=7.57, \mathrm{Cl}=2.018,28.445, p=0.000)$, in thin body conditioned cattle than good body conditioned $(\mathrm{OR}=10.347, \mathrm{Cl}=1.769,60.520, \mathrm{p}=0.013)$. Plastic was the most commonly encountered $(56.9 \%)$ foreign material in all study animals, followed by cloth $(13.8 \%)$, rope and mixed $(9.2 \%)$, wire $(6.4 \%)$ and nail $(5.5 \%)$. In all species the proportion of indigestible foreign body in rumen $(77.1 \%)$ were significantly higher than reticulum $(22.9 \%)(\mathrm{OR}=3.8365, \mathrm{Cl}=2.4086,6.1111, p=0.001)$.

Conclusion: This study revealed ingestion of different types of indigestible foreign bodies by ruminants in the study area which may pose serious health problem for free grazing ruminant and negatively affect their overall productivity and production. This strongly calls for concerned stakeholders to design and implement appropriate waste disposal practice and thereby reduces the chance of ingesting foreign bodies.

Keywords: Asella municipal abattoir; Indigestible foreign bodies; Postmortem study; Ruminants

\section{Introduction}

Ethiopia is resource full country endowed with larges population of livestock in Africa. The total cattle populations of the country is estimated to be about 57.83 million, whereas the number of small ruminants are estimated to exceed 58 million [1]. However, development this sector is hampered by different constraints and has not been fully exploited the benefit of indigenous livestock compared to its tremendous potential. significant losses result each year from the death of animals as a result of lack of appropriate veterinary services, lack of attention from government, wide spread endemic disease and recurrent drought [2]. Ingestible foreign body predisposed by environmental pollution is currently becoming a global health problem of ruminants and have been implicated as among common causes of sudden death $[3,4]$.

Different studies have shown that ruminants reared in urban and suburban areas have high probability to ingest indigestible materials such as plastic, cloth, wire, leather and metal $[5,6]$. Ingestion of indigestible foreign bodies by animals is mainly associated with nutritional deficiencies, environmental pollution and poor feeding management
[7]. According to different studies the common non-piercing foreign bodies commonly ingested by ruminants are plastic bags, sack thread, ropes, leather, rubber, bed linen, pieces of lead pipe, straw baskets, hair and plant fibers (bezoars) [4]. While wire, needles, nails and stones are the major penetrating foreign bodies isolated from ruminants $[8,9]$. In cattle, ingestion of foreign body was reported to be a condition of great economic importance as it causes loss of production and high mortality rates [10]. However, ingestion of indigestible foreign body can occur in small ruminant during periods of drought, food scarcity, nutritional

*Corresponding author: Nejash Abdela, School of Veterinary Medicine, College of Agriculture and Veterinary Medicine, Jimma University, Jimma Ethiopia, Tel: +251924124547; E-mail: nejash.abdela@gmail.com

Received February 17, 2017; Accepted April 01, 2017; Published April 03, 2017

Citation: Teshome E, Abdela N, Hassan A (2017) Postmortem Study on Indigestible Foreign Bodies in Rumen and Reticulum of Ruminants Slaughtered at Asella Municipal Abattoir, Southeastern Ethiopia. J Vet Sci Technol 8: 436. doi: 10.4172/2157-7579.1000436

Copyright: (C) 2017 Teshome E, et al. This is an open-access article distributed under the terms of the Creative Commons Attribution License, which permits unrestricted use, distribution, and reproduction in any medium, provided the original author and source are credited. 
Citation: Teshome E, Abdela N, Hassan A (2017) Postmortem Study on Indigestible Foreign Bodies in Rumen and Reticulum of Ruminants Slaughtered at Asella Municipal Abattoir, Southeastern Ethiopia. J Vet Sci Technol 8: 436. doi: 10.4172/2157-7579.1000436

Page 2 of 6

deficiency, pica and massive environmental pollution $[11,12]$.

Foreign body exposes ruminants to various forms of diseases such as glositis, esophagitis, ruminitis, impaction of rumen, traumatic pericarditis (TP) and traumatic reticulo peritonitis (TRP) are the possible health problems, which can be caused by the ingestion of foreign bodies by the ruminants [3]. Other harmful effects of foreign body include reduced feed intake, failure to absorb volatile fatty acids, reduced rate of weight gain, internal injury, and death following obstruction of the intestinal tract $[3,11]$. Nonmetallic indigestible foreign bodies in the reticulorumen cause recurrent rumen tympany in adult dairy cattle. Although the problems caused vary with the duration and location of the foreign body in the rumen or reticulum, the degree of obstruction in appetence, vomiting, diarrhea, lethargy and abdominal pains are clinical signs manifested by animals with foreign body [13].

In Ethiopia, ruminants are kept under poor extensive farming system and they are more likely to be exposed to ingestion of indigestible materials from different sources due to high environmental contamination with plastic bags and other materials. Despite the free grazing of ruminants in contaminated environments, there is limited information about prevalence and type of foreign bodies ingested by ruminants at national level in general and in Asella in particular. Therefore, the objectives of this study were to estimate the prevalence of foreign bodies in the rumen and reticulum of ruminants and identify the types of foreign bodies and risk factors associated with ingestion of indigestible foreign bodies in ruminant slaughtered at Asella municipal abattoir.

\section{Materials and Methods}

\section{Study area}

Asella is a capital of Arsi Zone, Oromia regional state. It is located about $175 \mathrm{~km}$ south east of Addis Ababa at $6^{\circ} 59^{\prime}$ to $8^{\circ} 49^{\prime} \mathrm{N}$ latitudes and $38^{\circ} 41^{\prime}$ to $40^{\circ} 44^{\prime} \mathrm{E}$ longitudes. The town and its surrounding is characterized by mid subtropical weather, with minimum and maxim temperature ranging from 8.4 to $22.6^{\circ} \mathrm{C}$, and the relative humidity ranging from 43 to $60 \%$. The area is characterized by two-phase rainfall occurring from March to April (short rainy season) and July to October (long rainy season) with average annual rainfall of $2000 \mathrm{~mm}$. The farmers in the area practice mixed crop-livestock farming system. According to Arsi Planning and Development Office (2007), the area is densely populated, with livestock population of 85,893 cattle, 57,118 sheep, 10,725 goats, 7841 horses, 15,642 donkeys, 517 mules and 35,489 poultry.

\section{Study population and study design}

A cross-sectional study was conducted from November, 2016 to January, 2017 in Asella municipal abattoir with the objective of estimating the prevalence of foreign bodies and to identify the type of foreign bodies in the study population. Animals included in this study were cattle, sheep, and goats with different body condition. The study animals are comprised of local breed with different age groups and most of them are managed under extensive management system. Regarding sex composition of study animals both males and females' small ruminants were included. However, only male cattle were included in this study as female cattle were not encountered in Asella municipal abattoir during study period. The cattle and sheep are originated from Sagure, Bekoji, and Asasa and most goats were brought from Habura.

Sample size determination and sampling technique
The sample size was determined based on the formula given by Thrusfield with $50 \%$ expected prevalence (no previous study in the study area), $5 \%$ desired level of precision and $95 \%$ of confidence interval. Accordingly the required samples for this study were 384 animals. However, to increase the precision 500 animals were examined. The data for this study was collected by visiting abattoir twice a week and the daily cattle and small ruminant slaughter at Asella municipal abattoir was $23-30$ and $17-30$, respectively. The study animals were selected from cattle, sheep and goats slaughtered during each visit day by using simple random sampling technique.

\section{Ante mortem and post mortem examination}

During ante mortem examination each selected animal was identified by providing a unique temporary identification number that could be used for post mortem examinations. Furthermore, the animals' species, sex, age and body conditions were recorded on special format prepared for this purpose. Age and body condition of the animals was determined based on standard given by Gatenby, Pace, Wakeman and Steele. The body condition of study animals were classified in to three, namely thin, medium, and good. Similarly, the age was also classified in to three which comprise $<2,2-3,>3$ for small ruminants and $<4,4-7$, and $>7$ for cattle. During postmortem examination, the stomach was removed from the abdominal cavity and rumen and reticulum were examined by visual inspection and palpation which were followed by incision and examination of the whole contents for the presence of foreign bodies. When foreign bodies are encountered, they were removed, washed, and identified and photographed while possible.

\section{Data management and analysis}

The data were first entered in to Microsoft Excel work sheet version 2010 and analyzed using Statistical Package for Social Sciences (SPSS) software version 20. Descriptive statistics was used to determine frequencies, percent and over all prevalence. The prevalence of indigestible foreign bodies was determined as a proportion of affected animals out of the total animal examined. Multivariate logistic regression analysis was used to calculate association between different factors and occurrence of indigestible foreign body in ruminants. A 95\% confidence interval of the OR and $p$-values were used to describe statistical significance associations. The association is judged as significant when p-value is less than 0.05 .

\section{Results}

\section{Prevalence of foreign body in relation to animal species}

From 500 ruminants ( 240 sheep, 60 goats and 200 cattle) examined for the presence of indigestible foreign bodies, 109 (21.8\%) animals were found positive for one or more indigestible foreign bodies in their rumen or reticulum. When sheep, goats and cattle There was significant difference $(\mathrm{p}=0.000)$ between species with higher prevalence in sheep (29.6\% and followed by goat (16.7\%) and cattle (14\%). The results indicate that sheep and goat were 2.581 and 1.229 times more likelihood to acquire foreign body than cattle, respectively. The detailed results for each species are shown in Table 1.

\section{Types and proportions of indigestible foreign bodies in the rumen and reticulum}

From indigestible foreign body encountered plastics were leading indigestible material (56.9\%) (Figures 1-3), followed by pieces of cloth (13.8\%), rope and mixed (plastic, rope and hair) $(9.2 \%)$, wire (6.4\%) and nail (5.5\%). In all species (ovine, caprine and bovine), the proportion of 
Citation: Teshome E, Abdela N, Hassan A (2017) Postmortem Study on Indigestible Foreign Bodies in Rumen and Reticulum of Ruminants Slaughtered at Asella Municipal Abattoir, Southeastern Ethiopia. J Vet Sci Technol 8: 436. doi: 10.4172/2157-7579.1000436

indigestible foreign body in rumen (77.1\%) were significantly higher than reticulum (22.9\%). The odd of foreign body occurrence in rumen was 3.8365 times more likely than reticulum $(\mathrm{OR}=3.8365, \mathrm{CI}=2.4086$, $6.1111, p=0.001)$. The types of foreign bodies encountered and their proportion in rumen and reticulum of various species of ruminants are summarized in Table 2 .

\section{Factors associated with indigestible foreign bodies ingestion}

Factors associated with indigestible foreign bodies ingestion in small ruminant: Out of 300 small ruminants (sheep $240(80 \%)$,

\begin{tabular}{|c|c|c|c|c|c|}
\hline $\begin{array}{c}\text { Animal } \\
\text { species }\end{array}$ & $\begin{array}{c}\text { Number of } \\
\text { examined }\end{array}$ & Prevalence & OR & $\mathbf{9 5 \%} \mathbf{C l}$ & P-Values \\
\hline Sheep & 240 & $71(29.6 \%)$ & 2.581 & $1.587,4.196$ & \\
\hline Goat & 60 & $10(16.7)$ & 1.229 & $0.559,2.701$ & \multirow{2}{*}{$\mathbf{0 . 0 0 0}$} \\
\hline Cattle & 200 & $28(14 \%)$ & Ref. & & \\
\hline
\end{tabular}

Table 1: Prevalence of foreign bodies in sheep, goats and cattle.

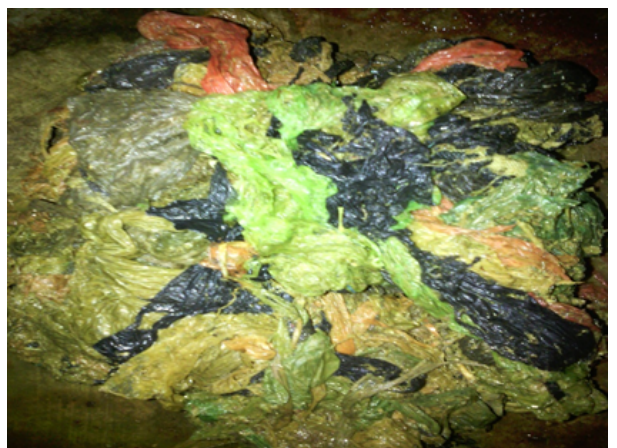

Figure 1: Plastic foreign body removed from bovine rumen.

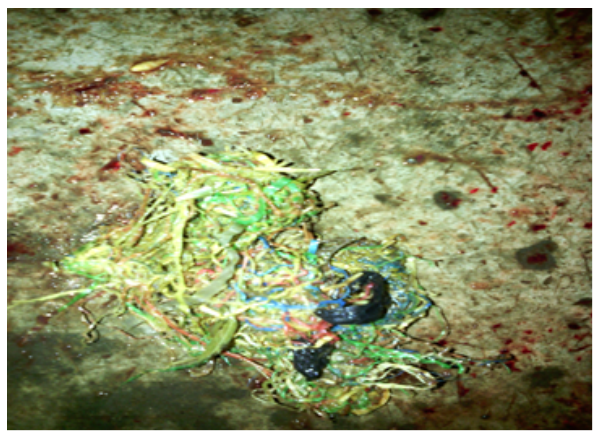

Figure 2: Mixed (Plastic and rope) recovered from rumen of goat

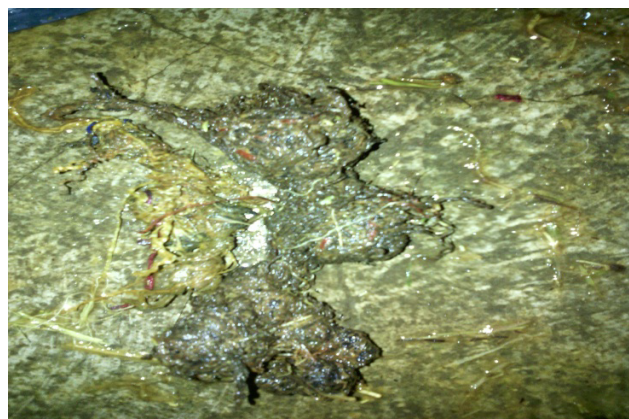

Figure 3: Calcified plastic from bovine reticulum and goats $60(20 \%)$ examined 81 animals were found to be positive for indigestible foreign bodies. Multivariable logistic regression analysis showed that the prevalence of indigestible foreign body were insignificantly higher $(\mathrm{p}=0.064)$ in sheep $(29.5 \%)$ than goats $(16.6 \%)$ and sheep were 2.074 times more likely to ingest foreign body than goats $(\mathrm{OR}=2.074, \mathrm{CI}, 0.958,4.486)$. The prevalence in relation sex was also found to be insignificantly higher in female (27.9\%) than male (23.9\%). Females were found to be 1.137 times more susceptible than males $(\mathrm{OR}=1.137, \mathrm{CI}=0.558,2.317, \mathrm{p}=0.723)$. Impaction due to foreign body occurred in small ruminant $<2$ years, $2-3$ years and $>3$ years were, $16.6 \%, 23.3 \%$ and $33.3 \%$, respectively. This difference was found to be statically significant $(p=0.031)$. Shoat $>3$ and $2-3$ years were 2.564 and 1.459 time more likely to ingest foreign body than small ruminant under 2 years. The highest prevalence was observed in shoat greater than 3 years $(\mathrm{OR}=2.564, \mathrm{CI}=1.160,5.670)$ and between 2 to 3 years $(\mathrm{OR}=1.459, \mathrm{CI}=0.601,3.541)$ than shoat less than 2 years.

Regarding the prevalence of indigestible foreign bodies in different body conditioned small ruminant, the highest occurrence of foreign body were recorded in animal with thin body condition score $(42.2 \%)$ followed by medium (23.7\%) and good body condition animals (17.3\%). There was statically significance deference between deferent body conditioned shoat $(p=0.002)$. Small ruminants with thin body conditioned were 3.361 time more likely to ingest indigestible foreign body than good body conditioned ( $\mathrm{OR}=3.361, \mathrm{C} \% \mathrm{I}=1.554,9.100)$. Similarly the odd of indigestible foreign body occurrence in medium body conditioned shoat was 1.378 times more likely than good body conditioned shoat. The numbers of animals examined in the various body condition categories and their corresponding prevalence are summarized in Table 3.

Prevalence of foreign body in relation to age and body condition of cattle: The prevalence in relation to age of cattle was $9.7 \%, 9.4 \%$ and $37.5 \%$ in cattle under 4 years, $4-7$ years and above 7 years and this difference was statically significant $(p=0.000)$. Multivariable logistic regression analysis indicated that cattle above 7 years are 7.57 times more likely to ingest indigestible foreign body than cattle under 4 years $(\mathrm{OR}=7.57, \mathrm{CI}=2.018,28.445)$. Similarly the odds of foreign body occurrence in cattle between $4-7$ years were 0.976 more likely than cattle under 4 years $(\mathrm{OR}=0.976, \mathrm{CI}=0.289,3.300)$ (Table 4$)$. The prevalence of foreign body in relation to body condition of cattle were also significantly different $(\mathrm{p}=0.013)$. The cattle with thin body conditioned are 10.347 more likely to ingest indigestible foreign bodies than good body conditioned cattle $(\mathrm{OR}=10.347, \mathrm{CI}=1.769,60.520)$. The odds of foreign body occurrence in medium body conditioned cattle were 4.198 more than good body conditioned cattle $(\mathrm{OR}=4.198$. $\mathrm{CI}=1.384,12.735)$.

\section{Discussion}

The current study showed an overall foreign body prevalence of $21.8 \%(109 / 500)$ in ruminants slaughtered at Asella municipal abattoirs. This study revealed relatively higher foreign body prevalence $(27 \%)$ in small ruminants (sheep (71/240 29.6\%), and goats (10/60, $16.7 \%$ ) than cattle $28 / 200(14 \%)$. This finding in line with Negash et al. who reported higher prevalence in small ruminants $(58.2 \%)$ than cattle (43.4\%) [7]. This may be due to the fact that most of cattle slaughtered in this abattoir had good body condition, which is indicate that cattle were reared with sufficient feed by owner. In contrast, most of small ruminant owners in this study area let their animal to forage on the highly polluted ground with no supplementary feed (Figure 4). If owners do not provide supplementary feed during feed shortages, 
Citation: Teshome E, Abdela N, Hassan A (2017) Postmortem Study on Indigestible Foreign Bodies in Rumen and Reticulum of Ruminants Slaughtered at Asella Municipal Abattoir, Southeastern Ethiopia. J Vet Sci Technol 8: 436. doi: 10.4172/2157-7579.1000436

Page 4 of 6

\begin{tabular}{|c|c|c|c|c|c|c|c|c|c|c|c|c|c|}
\hline \multirow{2}{*}{ Location } & \multirow{2}{*}{$\begin{array}{c}\text { Ruminant } \\
\text { species }\end{array}$} & \multicolumn{8}{|c|}{ Frequency and Type of foreign bodies } & \multicolumn{4}{|c|}{ Association } \\
\hline & & Plastic & Cloth & wire & Rope & Nail & Mixed & Subtotal Total & Overall & Prevalence & OR & $\begin{array}{c}95 \% \mathrm{Cl} \\
\mathrm{OR}\end{array}$ & P-Values \\
\hline \multirow{3}{*}{ Rumen } & Sheep & $35(49.3 \%)$ & $8(11.3 \%)$ & 0 & $4(5.6 \%)$ & $2(2.8 \%)$ & $9(12.7 \%)$ & $58(81.7 \%)$ & \multirow{3}{*}{$84(77.0 \%)$} & \multirow{3}{*}{$16.8 \%$} & \multirow{6}{*}{3.8365} & \multirow{6}{*}{$\begin{array}{l}2.4086 \\
6.1111\end{array}$} & \multirow{6}{*}{0.0001} \\
\hline & Goat & $4(40 \%)$ & $2(20 \%)$ & 0 & $2(20 \%)$ & 0 & $1(10 \%)$ & $9(90 \%)$ & & & & & \\
\hline & Cattle & $10(35.7 \%)$ & $4(14.3 \%)$ & 0 & $2(7.1 \%)$ & $1(3.5 \%)$ & 0 & $17(60.7 \%)$ & & & & & \\
\hline \multirow{3}{*}{ Reticulum } & Sheep & $7(9.9 \%)$ & 0 & $5(7 \%)$ & $1(1.4 \%)$ & 0 & 0 & $13(18.3 \%)$ & \multirow{3}{*}{$25(22.9 \%)$} & \multirow{3}{*}{$5 \%$} & & & \\
\hline & Goat & $1(10 \%)$ & 0 & 0 & 0 & 0 & 0 & $1(10 \%)$ & & & & & \\
\hline & Cattle & $5(17.9 \%)$ & $1(3.6 \%)$ & $2(7.1 \%)$ & $1(3.6 \%)$ & $3(10.7 \%)$ & 0 & $11(39.3 \%)$ & & & & & \\
\hline \multicolumn{2}{|c|}{ Total } & $56.9 \%$ & $13.8 \%$ & $6.4 \%$ & $9.2 \%$ & $5.5 \%$ & $9.2 \%$ & $100 \%$ & $100 \%$ & $21.8 \%$ & & & \\
\hline
\end{tabular}

Table 2: Types and proportions of indigestible foreign bodies in the rumen and reticulum of ruminant species.

\begin{tabular}{|c|c|c|c|c|c|c|c|c|c|c|c|c|}
\hline \multirow{2}{*}{\multicolumn{2}{|c|}{$\begin{array}{c}\text { Risk } \\
\text { Factors }\end{array}$}} & \multirow{4}{*}{\begin{tabular}{|c|}
$\begin{array}{c}\text { Number } \\
\text { Examined }\end{array}$ \\
240 \\
60 \\
\end{tabular}} & \multicolumn{6}{|c|}{ Frequency and prevalence of different indigestible foreign bodies } & \multirow{4}{*}{\begin{tabular}{|c|} 
Prevalence (\%) \\
$71(29.5)$ \\
$10(16.6)$ \\
\end{tabular}} & \multirow{4}{*}{$\begin{array}{c}\text { OR } \\
2.074\end{array}$} & \multirow{4}{*}{$\begin{array}{r}95 \% \mathrm{Cl} \text { of OR } \\
0.958,4.486\end{array}$} & \multirow{4}{*}{\begin{tabular}{|r|} 
P-Values \\
0.064
\end{tabular}} \\
\hline & & & \multirow{2}{*}{$\begin{array}{c}\begin{array}{c}\text { Plastic } \mathbf{n} \\
(\%)\end{array} \\
42(17.5)\end{array}$} & \multirow{2}{*}{\begin{tabular}{|c|} 
Cloth n (\%) \\
$8(3.3)$
\end{tabular}} & \multirow{2}{*}{\begin{tabular}{|c|} 
Wire n (\%) \\
$5(2.1)$
\end{tabular}} & \multirow{2}{*}{\begin{tabular}{|c|} 
Rope n (\%) \\
$5(2.1)$
\end{tabular}} & \multirow{2}{*}{$\begin{array}{c}\text { Nail } \mathbf{n}(\%) \\
2(0.8)\end{array}$} & \multirow{2}{*}{$\begin{array}{c}\begin{array}{c}\text { Mixed n } \\
(\%)\end{array} \\
9(3.8)\end{array}$} & & & & \\
\hline Sneciec & Sheep & & & & & & & & & & & \\
\hline specles & Goat & & $5(8.3)$ & $2(3.3)$ & 0 & $2(3.3)$ & 0 & $1(1.7)$ & & & & \\
\hline \multirow{2}{*}{ Sex } & Male & 67 & $7(10.4)$ & $2(3)$ & $1(1.5)$ & $4(6)$ & 0 & $2(3)$ & $16(23.9)$ & \multirow[b]{2}{*}{1.137} & \multirow[b]{2}{*}{$0.558,2.317$} & \multirow[b]{2}{*}{0.723} \\
\hline & Female & 233 & $40(17.2)$ & $8(3.4)$ & $4(1.7)$ & $3(1.3)$ & $2(0.9)$ & $8(3.4)$ & $65(27.9)$ & & & \\
\hline \multirow{3}{*}{ Age } & $<2$ years & 60 & $7(11.7)$ & $1(1.7)$ & 0 & 0 & $1(1.7)$ & 1(1.7) & $10(16.6)$ & Ref. & & \multirow{3}{*}{0.031} \\
\hline & $2-3$ & 90 & $11(12.2)$ & $4(4.4)$ & 1(1.1) & $2(2.2)$ & 0 & $3(3.3)$ & 21(23.3) & 1.459 & $0.601,3.541$ & \\
\hline & $>3$ years & 150 & $29(19.3)$ & $5(3.3)$ & $4(2.7)$ & $5(3.3)$ & $1(0.7)$ & $6(4)$ & $50(33.3)$ & 2.564 & $1.160,5.670$ & \\
\hline \multirow{4}{*}{ BCS } & Thin & 71 & $16(22.5)$ & $3(4.2)$ & $2(2.8)$ & $3(4.2)$ & 0 & $5(7)$ & $30(42.2)$ & 3.361 & $1.554,9.100$ & \multirow{3}{*}{0.002} \\
\hline & Medium & 177 & $29(16.4)$ & $5(2.8)$ & 0 & $2(1.1)$ & $2(1.1)$ & $4(2.2)$ & $42(23.7)$ & 1.378 & $0.601,3.163$ & \\
\hline & Good & 52 & $2(3.8)$ & $2(3.8)$ & $2(3.8)$ & $1(1.9)$ & 0 & $1(1.9)$ & $9(17.3)$ & Ref. & & \\
\hline & Total & 300 & $47(15.6)$ & $10(3.33)$ & $4(1.33)$ & $6(2)$ & $1(0.33)$ & $10(3.33)$ & & & & \\
\hline
\end{tabular}

Table 3: Multivariable logistic regression analysis output of factors associated with indigestible foreign body occurrence in small ruminant.

\begin{tabular}{|c|c|c|c|c|c|c|c|c|c|c|c|}
\hline \multicolumn{2}{|c|}{ Risk Factors } & No. Examined & Plastic (\%) & Cloth (\%) & Wire (\%) & Rope (\%) & Nail (\%) & Prevalence (\%) & OR & $95 \% \mathrm{Cl}$ & P-Values \\
\hline \multirow{3}{*}{ Age } & $<4$ years & 41 & $1(2.4)$ & $2(4.9)$ & 0 & $1(2.4)$ & 0 & $4(9.7)$ & Ref. & & \multirow{3}{*}{0.000} \\
\hline & $4-7$ & 127 & $7(5.5)$ & $1(0.8)$ & $2(1.6 \%)$ & $1(0.8)$ & $1(0.8)$ & $12(9.4)$ & 0.976 & $0.289,3.300$ & \\
\hline & 7 years & 32 & $7(21.9)$ & $2(6.3)$ & 0 & $1(3.1)$ & $3(9.4)$ & $12(37.5)$ & 7.577 & $2.018,28.445$ & \\
\hline \multirow{3}{*}{$\begin{array}{c}\text { Body } \\
\text { condition }\end{array}$} & Thin & 10 & $1(10)$ & $2(20)$ & 0 & 0 & 0 & $3(30)$ & 10.347 & $1.769,60.520$ & \multirow{3}{*}{0.013} \\
\hline & Medium & 113 & $11(9.7)$ & $3(2.7)$ & $2(1.8 \%)$ & $2(1.8)$ & $2(1.8)$ & $20(17.6)$ & 4.198 & $1.384,12.735$ & \\
\hline & Good & 77 & $3(3.9 \%)$ & 0 & 0 & $1(1.3 \%)$ & $2(2.6 \%)$ & $5(6.5)$ & Ref. & & \\
\hline
\end{tabular}

Table 4: Multivariable logistic regression analysis output of factors associated with indigestible foreign body occurrence in cattle.

their animals are likely to face a negative energy balance that will force them to ingest unusual materials including plastic, cloth, rope and even metallic objects Furthermore, most all bovine slaughtered in Asella municipal abattoir were male and this may also be associated lower prevalence in cattle.

Small ruminant overall prevalence (27\%) approximate o the findings of Fasil et al. who reported $30.73 \%$ in Jigjiga municipal abattoir [14]. However, this finding is higher than study by Roman and Hiwot (23.4\%), Igbokwe et al. (19.3\%), Bwala et al. (16.5\%), Otsyina et al. (10.8\%), Tesfaye et al. (6.1\%), Abebe and Nuru (9.2\%) [11,12,15-18]. This difference in the prevalence of foreign bodies between different areas may be associated with differences in animals' management system, age of animal slaughtered, sex and the extent of foreign body management between different study areas.

In the present study, the occurrence of foreign bodies was insignificantly higher $(\mathrm{P}=0.064)$ in sheep than goats during multi variable logistic regression analysis which is accordance with the report of Sheferaw et al. [19]. This variation could be associated with the selective feeding nature of goats as they usually browse on bushes and shrubs thus putting them at a relatively lower risk of ingesting foreign materials from the ground and origin of animal may also contribute for lower prevalence. Since most sheep slaughtered at Asella municipal abattoir were brought from per urban area, they were relatively at risk to graze on contaminated grazing area.

Although it is not significant, higher prevalence of foreign body was also observed in females (27.9\%) than males (23.9\%). This is in contrast with the reports of Remi-Adewunmi et al. [6]. However, higher prevalence of indigestible foreign bodies in female sheep and goats have also been reported by other authors $[11,12,15,18,20]$. This may be due to increased appetite of female animals and high nutritional demands during gestational period.

According to this study shoat with age greater than 3 years are frequently affected with indigestible materials than the shoat aged less than 2 years and 2-3 groups. The current finding was different from report of Otsyina HR et al. who encountered plastic bags most frequently in sheep and goats in the 2-3 years old age group (37.5\%) followed by those in the 1-2 year old age group (24.1\%) and absence of foreign material in animals older than 4 years [13]. However, this finding is in agreement with Hailat et al., Igbokwe et al., RemiAdewunmi et al., Roman and Hiwot, Abebe and Nuru, Saulawa et al. 
Citation: Teshome E, Abdela N, Hassan A (2017) Postmortem Study on Indigestible Foreign Bodies in Rumen and Reticulum of Ruminants Slaughtered at Asella Municipal Abattoir, Southeastern Ethiopia. J Vet Sci Technol 8: 436. doi: 10.4172/2157-7579.1000436

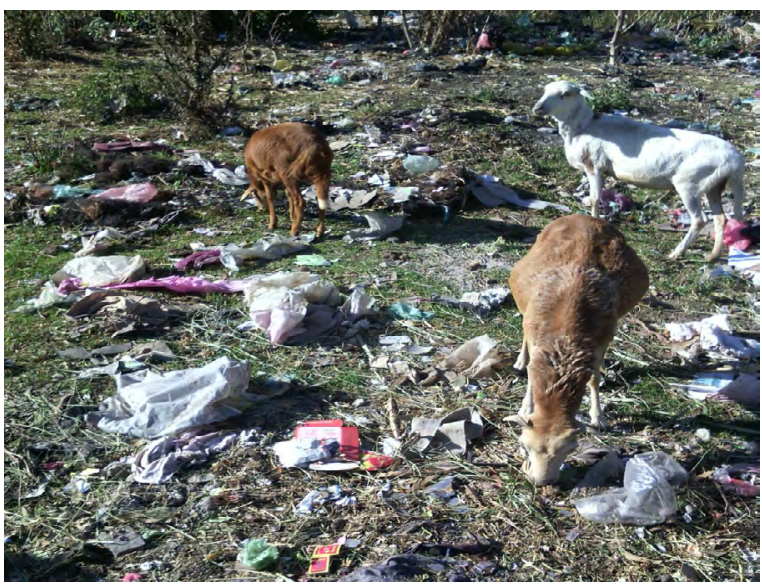

Figure 4: Photo taken from animals grazing in contaminated area in Asella town.

Tesfaye et al. [11,15,18,20-23]. This may happen because of ingestion of indigestible substances over a prolonged period.

Overall the prevalence of foreign bodies in small ruminant with poor body condition of $(45.8 \%)$ was significantly higher $(\mathrm{p}=0.002)$ than in those with medium (23.2\%) and good body condition (15.4\%). This finding is in agreement with the reports of Hailat et al., Igbokwe et al., Remi-Adewunmi et al., Roman and Hiwot, Abebe and Nuru, Saulawa et al., Tesfaye et al. [6,11,15,18,21-23]. This may be because of thin body condition animals consuming without selection to compensate there energy balance. As a result poor body condition of animals with indigestible foreign bodies was attributed to reduction in volatile fatty acids absorption from rumen and this result in inappetence, abdominal distention, reduced weight gain, lack of defecation with consequent emaciation and recumbence [11].

The prevalence of foreign bodies observed in cattle (14\%) was in approximate agreement with the report of Tesfaye et al. $13.22 \%$, Akinbobola (12\%), Mushonga et al. (17.4\%) and Bassa and Tesfaye (17.16\%) [17,24,25].

However, this finding is lower when compared to Negash et al. (43.4\%), Sheferaw et al. (41.8\%) and Anwar et al. (59.14\%) $[7,4,19]$. This is may be due to sex factor, bread, and management difference. Prevalence of foreign bodies in cattle with poor body condition was $30 \%$ which is significantly higher $(\mathrm{p}=0.013)$ than in those with medium $(17.6 \%)$ and good body condition (7.8\%). This finding is in agreement with the reports of Hailat et al. and Negash et al. [7,22].

Accumulations of indigestible foreign bodies were significantly higher in rumen $(\mathrm{p}=0.001)$ of all study animal than in the reticulum. This finding was in agreement with the findings of Abebe and Nuru, Roman and Hiwot, Tesfaye et al. and Negash et al. $[7,15,17,18]$. This may be because of the larger rumen volume, the cumulative size/s and material composition of the foreign bodies, and the types of materials, with metals and sharp objects tending to localized preferentially in reticulum [3]. Plastic was the most commonly encountered (56.9\%) foreign material in all study animals, followed by cloth (13.8\%), rope and mix (9.2\%), wire (6.4\%) and nail (5.5\%). This finding is in general agreement with various reports from different areas of Ethiopia (Abebe and Nuru, Roman and Hiwot, Sheferaw et al., Tesfaye et al.) [15,1719], Nigeria (Igbokwe et al., Remi- Adewunmi et al.) $[6,11]$ and Jordan (Hailat et al.) [22]. This indicates the widespread use of plastic bags in these areas and environmental pollution due to their improper disposal.

Conclusively this study indicated $21.8 \%$ prevalence of indigestible foreign body in rumen and reticulum of ruminants in study area which is an indication of poor environmental protection and pollution with plastics and other indigestible foreign bodies. Thus, order to avert the problem emergency designing and implementation of appropriate waste disposal practice is urgently required to reduce environmental pollution thereby enhances livestock production and productivity. Furthermore, Creation of awareness for animal owners is necessary to avoid the risk of foreign body ingestion by their animals.

\section{Acknowledgements}

We would like to thanks Asella municipal abattoir workers for their cooperation while conducting this research. Authors are also thankful to Jimma University for provision of required facility.

\section{Conflict of Interest}

Authors declare no conflict of interest.

\section{References}

1. CSA (2016) Federal democratic republic of Ethiopia. Central statistical agency. Agricultural sample survey, Volume II, Report on livestock and livestock characteristics. Statistical bulletin 583, Addis Ababa, Ethiopia.

2. Abdela N, Jilo K (2016) Impact of Climate Change on Livestock Health: A Review. Global Veterinaria 16: 419-424.

3. Radostits OM, Gay CC, Hinchcliff KW, Constable PD (2007) Veterinary medicine: A textbook of the diseases of cattle, horses, sheep, pigs and goats. 10th edn., Saunders, Elsevier, London.

4. Anwar K, Khan I, Aslam A, Mujtaba M, Din A, et al. (2013) Prevalence of indigestible rumen and reticulum foreign bodies in Achai cattle at different regions of Khyber Pakhtunkhwa. ARPN Journal of Agricultural and Biological Science 8: 580-586.

5. Abdullah US, Usman GSH, Mshelia TA (1984) Impaction of rumen with indigestible garbage in cattle and sheep reared within urban and sub-urban environment. Nigerian Veterinary Journal 13: 89-95.

6. Remi-Adewunmi BD, Gyang EO, Osinowo AO (2004) Abattoir survey of foreign body rumen impaction in small ruminants. Nigerian Veterinary Journal 25: 32-38.

7. Negash S, Sibhat B, Sheferaw D (2015) A postmortem study on indigestible foreign bodies in the rumen and reticulum of ruminants, eastern Ethiopia. Onderstepoort J Vet Res 82

8. Nugusu S, Velappagounder R, Unakal C, Nagappan R (2013) Studies on Foreign Body Ingestion and their Related Complications in Ruminants Associated with Inappropriate Solid Waste Disposal in Gondar Town, North West Ethiopia. International Journal of Animal and Veterinary Advances 5: 67-74.

9. Ramaswamy V, Sharama H (2011) Plastic bags threat to environmental and cattle health: A retrospective study from Gondar city of Ethiopia. The IIOAB Journal 2: 7-12.

10. Ramin AG, Shoorijeh SJ, Ashtiani HRA, Naderi MM, Behzadi MA et al. (2008) Removal of metallic objects from animal feeds: Development and studies on a new machine. Veterinary Scan 3: 1-6.

11. Igbokwe IO, Rolo MY, Egwu GO (2003) Rumen impaction in sheep with indigestible foreign bodies in the semi-arid of Nigeria. Small Ruminant Research 49: 141-146.

12. Otsyina HR, Nguhiu-Mwangi J, Mogoa EGM, Mbuthia, Ogara WO (2015) Prevalence of indigestible rumen foreign bodies in sheep and goats at Dagoretti and Kiserian Abattoirs, Kenya. Inter J Vet Sci 4: 75-80.

13. Makhdoomi D, Gazi M, Parah J (2012) Foreign body syndrome- etiology, clinical symptoms, diagnosis and treatment: A review. International Journal of Livestock Research. 2: 48-52.

14. Fasil N (2016) Assessment of Sheep and Goat Foreign Bodies in Rumen and Reticulum in the Jigjiga Municipal Abattiar. Advances in Dairy Research 1-6.

15. Roman T, Hiwot $Y$ (2010) Occurrence of rumen foreign bodies in sheep and 
Citation: Teshome E, Abdela N, Hassan A (2017) Postmortem Study on Indigestible Foreign Bodies in Rumen and Reticulum of Ruminants Slaughtered at Asella Municipal Abattoir, Southeastern Ethiopia. J Vet Sci Technol 8: 436. doi: 10.4172/2157-7579.1000436

Page 6 of 6

goats slaughtered at the Addis Ababa Municipality Abattoir. Ethiop Vet $\mathrm{J} 14$ : $91-100$.

16. Bwala DA, Peter ID, Eze CA, Bukar-Kolo YM, Bukar MM (2016) A Study on Rumen Foreign Body Impaction in Sheep Slaughtered at the Maiduguri Metropolitan Abattoir, Maiduguri, Nigeria. Int J Livest Res 6: 16-23.

17. Tesfaye D, Daba D, Mekibib M, Fekadu A (2012) The problem of environmenta pollution as reflected in the fore stomach of cattle: A postmortem study in Eastern Ethiopia. Global Journal of Environmental Research 6: 61-65.

18. Abebe F, Nuru M (2011) Prevalence of indigestible foreign body ingestion in small ruminants slaughtered at Luna export abattoir, East Shoa, Ethiopia. Journal of Animal and Veterinary Advances 10: 1598-1602.

19. Sheferaw D, Fikreysus G, Metenyelesh A, Tesfaye D, Etana D (2014) Ingestion of indigestible foreign materials by free grazing ruminants in Amhara Region, Ethiopia. Trop Anim Health Prod 46: 247-250.

20. Omidi A, Naeemipoor H, Hosseini M (2012) Plastic debris in thedigestive tract of sheep and goats: An increasing environmental contamination in Birjand, Iran. Bull Environ Contam Toxicol 88: 691-694.
21. Saulawa MA, Ukashatu S, Garba MG, Magaji AA, Bello MB et al. (2012) Prevalence of indigestible substances in rumen and reticulum of small ruminants slaughtered at Katsina central abattoir, Katsina State, Nigeria. Sci J Pure Appl Sci 1: 17-21.

22. Hailat N, Nouh S, AAl-Darraji, SFLafi, Al-Aniand FA (1997) Prevalence and pathology of foreign bodies (plastics) in Awassi sheep in Jordan. Small Rum Res 24: 43-48.

23. Tesfaye D, S Yismaw, Demissie T (2012) Ruminal and reticular foreign bodies in small ruminants slaughtered at Jimma Municipal abattoir, Southwestern Ethiopia. J Vet Adv 2: 434-439.

24. Akinbobola JS, Omeje JN, Akinbobola RI, Ayoade RI, Ajagbe OA, et al. (2016) Prevalence of Indigestible Foreign Bodies in the Rumen of Cattle Slaughtered at Gwagwalada Abattoir, Abuja, Nigeria. International Journal of Livestock Research 6: 25-31.

25. Mushonga B, Habarugira G, Musabyemungu A, Udahemuka J, Jaja F, et al (2015) Investigation of foreign body in the forestomach of cattle at Ngoma slaughterhouse, Rwanda. J S Afr Vet Assoc 86: 1233. 